\title{
Design of Differential-Fed Filtering Patch Antenna with High-Gain and Dual-Polarized Characteristics for 5G Systems
}

\author{
Yasir I. A. Al-Yasir ${ }^{1}$, Mustafa Bakr², Naser Ojaroudi Parchin ${ }^{1}$, Ahmed Abdulkhaleq ${ }^{1,3}$, \\ Hassan Migdadi ${ }^{4}$, Raed Abd-Alhameed ${ }^{1}$ \\ \{Y.I.A.Al-Yasir@bradford.ac.uk\} \\ ${ }^{1}$ Faculty of Engineering and Informatics, University of Bradford, Bradford, UK \\ ${ }^{2}$ Institute of Microwave and Photonics, University of Leeds, Leeds, UK \\ ${ }^{3}$ SARAS Technology, Leeds, UK \\ ${ }^{4}$ Greater Amman Municipality, Jordan
}

\begin{abstract}
In this paper, a new high-gain differential-fed dual-polarized microstrip filtering antenna with high common-mode rejection is presented. Two differential pairs of probe feeding ports are utilized to provide differentially exciting signals. The filtering response is achieved by introducing four symmetrical open-loop ring resonator slots on the top layer surrounding the four excitation ports of the patch antenna. The resonators can produce nulls at the low edge of the passband bandwidth with high gain and wide stopband characteristics. Because of the strictly symmetric configuration of the proposed antenna, the design is studied and analyzed only in one polarization configuration. Compared with other presented filtering antenna designs, the proposed design has not only high gain and dual-polarized characteristics but also introduces high efficiency and much lower crosspolarization level due to the differentially driven ports. The filtering antenna is designed, simulated and optimized using computer simulation technology (CST) software using a Rogers TMM3 substrate with a relative dielectric constant of 3.45. Also, the antenna has a single layer substrate with a height of 0.035 of the free space wavelength and operating at $3.54 \mathrm{GHz}$ for $5 \mathrm{G}$ communications.
\end{abstract}

Keywords: Filtering antenna, CST, differentially-fed, Dual-Polarized, high-gain, microstrip.

\section{Introduction}

As indicated by the office of communication (Ofcom), sub $6 \mathrm{GHz}(3.4-3.8 \mathrm{GHz})$ spectrum has been allocated for fifth generation (5G) and many modern microwaves (MW) and radio frequency (RF) components such as antennas, filters and power amplifiers [1-25]. Thus, microstrip antennas with filtering performance, high gain, high isolation, high front-to-back ratio (FTBR), stable radiation pattern, good common-mode (CM) rejection level and unidirectional radiation pattern in the planar configuration simultaneously are necessary for $5 \mathrm{G}$ applications [26-31]. Recently, dual-polarized and differential-fed techniques have been extensively introduced to improve the performance of the microwave and RF systems [32-34]. Different differential-fed antennas have been reported, such as planar antennas [35-38], magneto-electric dipole antennas [39, 40], 3D-backed antennas [41], and so on. A differential 
planar antenna presented in [35] is fed by $0^{\circ}$ and $180^{\circ}$ signals, providing low cross-polarization, wide bandwidths, and high gain. The presented design has a bandwidth of $13 \mathrm{GHz}$ and resonates at $13.2 \mathrm{GHz}$ for $\mathrm{Ku}$-band wireless applications. Unlike conventional differentially fed microstrip antennas, the designs proposed in [36] and [37] employ a folded plate pair as the differential feeding approach. The proposed antennas have stable realized gains around $8 \mathrm{~dB}$ within the operating bandwidth, providing high stability of the radiation patterns with the symmetrical performance for the two resonating modes. A differential-fed planar antenna with a realized gain of $8.2 \mathrm{dBi}$ and a $130 \mathrm{MHz}$ bandwidth is presented in [38]. The designed antenna can serve different applications such as energy harvesting, Radio-frequency identification (RFID) tags and differential/balanced circuits.

The above-mentioned differential-fed microstrip antennas operating with a single polarization radiation pattern. Dual-polarized antennas provide polarization diversities to decrease the side effect of multipath fading or improve channel capacity are presented in [42]. They find prospective application in many wireless communications, especially in base stations of cellular mobile phones. Nevertheless, there are few researchers proposed differential-fed dual-polarized microstrip antennas [43, 44]. In [43], a dual-polarized cavity-backed planar antenna with differentially driven coaxial feeds is introduced. In this antenna, both polarizations can be tuned from $0.65 \mathrm{GHz}$ to $1.2 \mathrm{GHz}$ using $(1.2-5.4 \mathrm{pF})$ varactor diodes. Besides, the fractional bandwidth differs from $1 \%$ to $2 \%$ over that range.

In this work, a new differentially fed, dual-polarized, and high gain filtering antenna is designed, simulated and implemented. Four half-wavelength open-ring slots are loaded to the radiating patch as resonator filters to provide the filtering characteristics. The filtering antenna is designed on a Rogers TMM3 substrate with a relative dielectric constant of 3.45 , loss tangent $=0.002$ and thickness $\mathrm{h}=3.2 \mathrm{~mm}$, and is simulated and optimized using finite element solver software (CST) simulator. Because of the differentially-driven and strict symmetrical geometry, very good performance including high stability of the radiation pattern characteristics, high isolation, good CM rejection, low-cross polarization level with filtering characteristics are obtained. All of these merits make the presented microstrip antenna suitable for the sub- $6 \mathrm{GHz}$ $5 \mathrm{G}$ communications. The proposed dual-polarized filtering antenna is fabricated and measured, and good agreement is achieved between the simulated and measured results.

\section{Differentially fed filtering patch antenna design and configuration}

The geometry of the proposed dual-polarized differentially driven microstrip filtering antenna is shown in Fig. 1. The filtering antenna is designed on a Rogers TMM3 substrate with a relative dielectric constant of 3.45, loss tangent $=0.002$, and thickness $\mathrm{h}=3.2 \mathrm{~mm}$. The proposed filtering antenna composites of circular dick radiating patch four metallic shorting vias and two pairs of differential feeding probes. The differentially fed port 1 is composed of port $1+$ and port $1-$, whereas the differential-fed port 2 is composed of port $2+$ and port $2-$. Adding slots with different shapes to the radiating patch can affect the surface current densities or excite specific frequency modes. Therefore, the antenna size can be reduced with improved performance. In our paper, the slots are loaded on the antennas to provide a broadside radiationpattern nulls at the upper edge of the in-band antenna frequency response, providing filtering response with wide stopband rejection. The presented antenna consists of four open-loop ring slots, which are loaded on the top layer of the radiating patch. The total length of each slot is about half the wavelength of the resonant frequency. CST software is used for analyses and 
simulations to obtain optimal design configuration. As the initial parameters of the CST simulator, the actual radius of the patch $(R)$ at the resonant frequency $f_{0}$ can be calculated as [45]

$$
\mathrm{R}_{\mathrm{e}}=\mathrm{R}\left\{1+\frac{2 \mathrm{~h}}{\pi \varepsilon_{\mathrm{r}} \mathrm{h}}\left[\ln \left(\frac{\pi \mathrm{R}}{2 \mathrm{~h}}\right)+1.7726\right]\right\}^{1 / 2}
$$

Where $\mathrm{h}$ and $\varepsilon_{\mathrm{r}}$ represent the height and permittivity of the substrate, respectively.

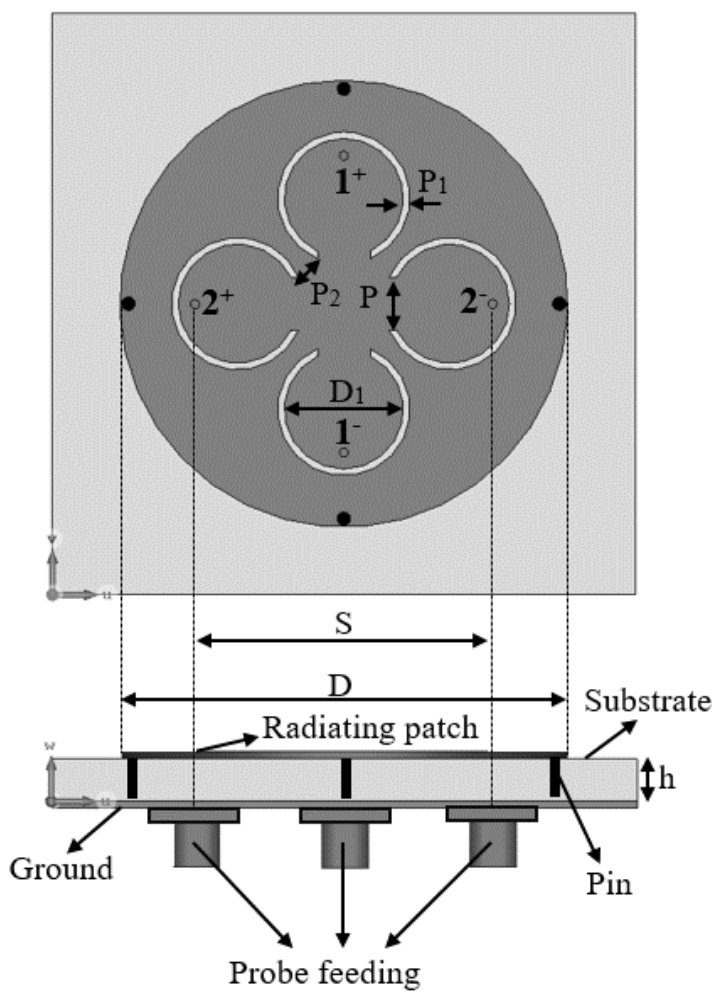

Fig. 1. Top- and side- view of the introduced differentially fed design.

In this work, CST software is used for analyses and simulations to obtain optimal design configurations. Table 1 summarizes the final optimized dimensions of the proposed high-gain differential-fed dual-polarized filtering microstrip antenna. The simulated current distributions of the proposed filtering antenna at differential port 1 and port 2 excitations at the resonant frequency are illustrated in Fig. 2.

Table 1. Dimensions of the proposed filtering microstrip antenna.

\begin{tabular}{cccccccc}
\hline Parameters & $\mathrm{D}$ & $\mathrm{D}_{1}$ & $\mathrm{~S}$ & $\mathrm{P}$ & $\mathrm{P}_{1}$ & $\mathrm{P}_{2}$ & $\mathrm{~h}$ \\
\hline Values $(\mathrm{mm})$ & 29 & 7.5 & 20 & 4 & 0.5 & 2 & 3.2 \\
\hline
\end{tabular}




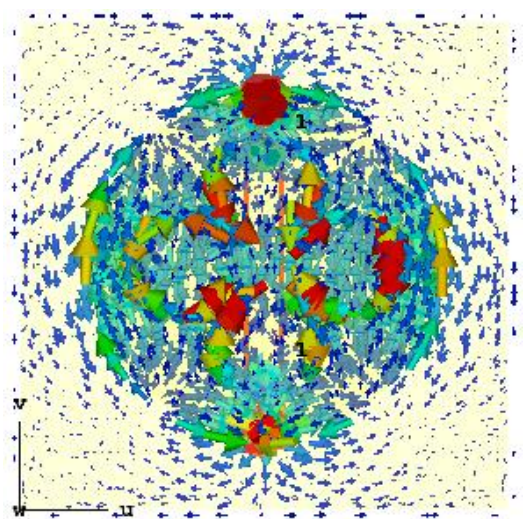

$\mathbf{0}, 1,(\mathbf{A} / \mathbf{m})$

(a)

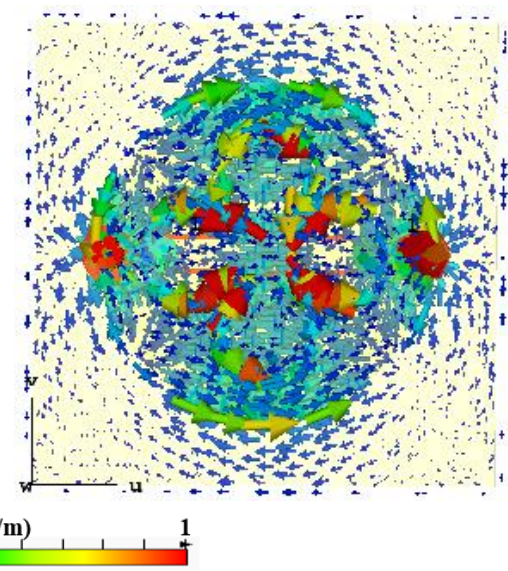

(b)

Fig. 2. The current distribution of the introduced differentially fed structure at $3.54 \mathrm{GHz}$. (a) Feeding port 1. (b) Feeding port 2.

By feeding differential port 1 only, the current density is concentrated on the longitudinal axis around the two ports (port 1+ and port 1-). On the other hand, by exciting differential port 2 only, the current density is concentrated on the transverse axis around the two ports (port 2+ and port 2-), and thus, providing two orthogonal polarizations.

\section{Filtering patch antenna performance}

In this section, filtering antenna characteristics in terms of reflection coefficient, peak realized gain, efficiency, and radiation pattern are presented and discussed. As long as the proposed patch antenna has a strict symmetry configuration, therefore the characteristics in only one polarization scenario (port $1^{+}$and port $1^{-}$) are studied to show the filtering performance of the antenna, while the performance will be identical on the second state. Figs. 3 and 4 show the differential reflection coefficients of the presented filtering antenna. The obtained performance illustrates that the filtering antenna resonances at the sub- $6 \mathrm{GHz} 3.54 \mathrm{GHz}$. The performance shows that the filtering antenna has less than $-25 \mathrm{~dB}$ reflection coefficient at resonance, with a fractional bandwidth of $2 \%$ (see Fig. 3). Besides, and under exciting the two differential ports, the isolation between the two ports is plotted in Fig. 4. Good polarization isolation, greater than $65 \mathrm{~dB}$, is obtained between the two differential ports.

The total simulated efficiency for the presented dual-polarized antenna is illustrated in Fig. 5, it can be shown that the total efficiency is greater than $80 \%$ through the operating bandwidth, whereas it is less than $10 \%$ through the stopband spectrum. Next, the far-field normalized radiation patterns are simulated and presented under the excitation of the differential-fed port 1 (port $1+$ and port $1-$ ). The radiation patterns are simulated in the $\mathrm{xz}$ - and $\mathrm{yz}$ - planes at the resonant frequency (see Fig. 6). In the xz-plane, the achieved cross-polarization (x-pol) level is calculated to be $85 \mathrm{~dB}$ lower than the corresponding value of the achieved copolarization (Co-pol) level. On the other hand, in the yz-plane, the achieved cross-polarization (x-pol) level is calculated to be $70 \mathrm{~dB}$ lower than the corresponding value of the achieved copolarization (Co-pol) level. 


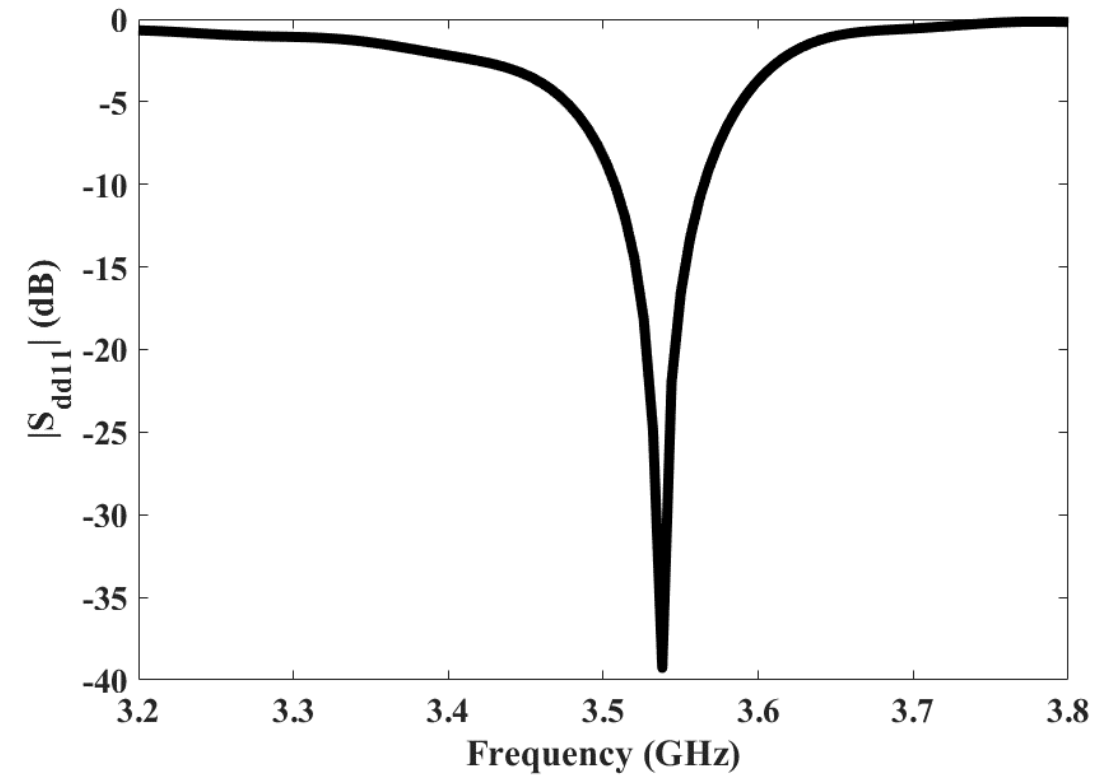

Fig. 3. $\mid$ Sdd11| results of the proposed differential-fed dual-polarized microstrip filtering antenna.

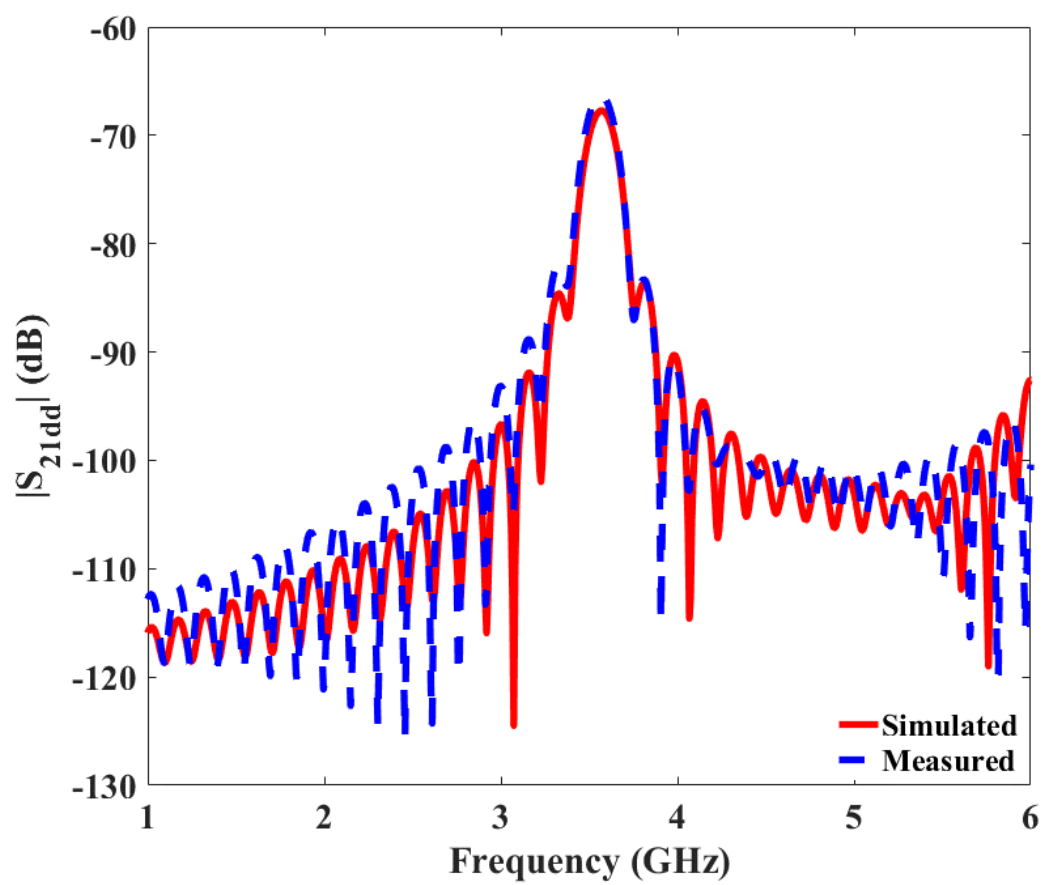

Fig. 4. $\left|\operatorname{Sdd}_{12}\right|$ results of the proposed differential-fed dual-polarized microstrip antenna. 


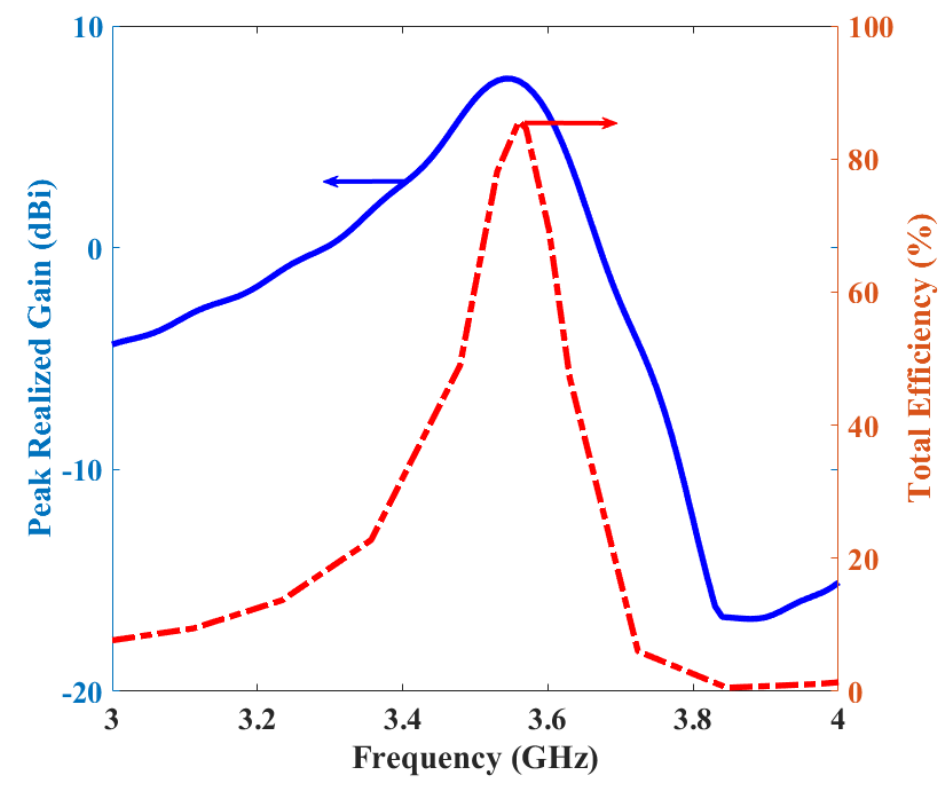

Fig. 5. The total efficiency and gain of the proposed differential -fed microstrip filtering antenna.

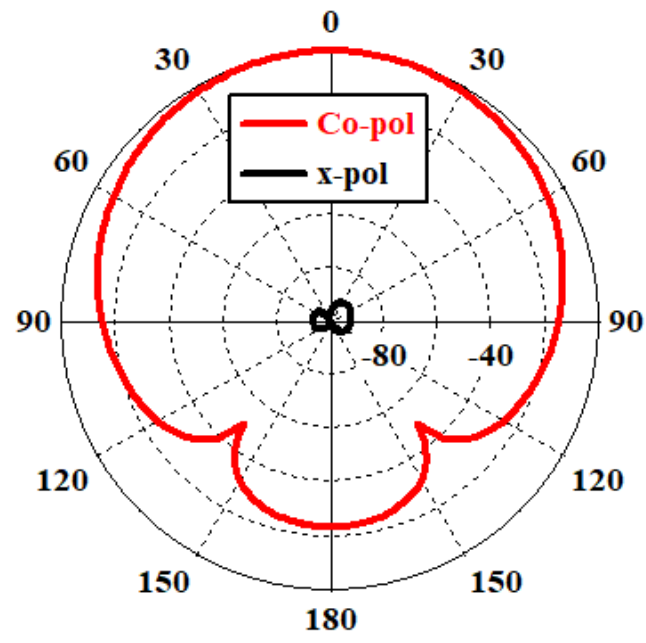

(a)

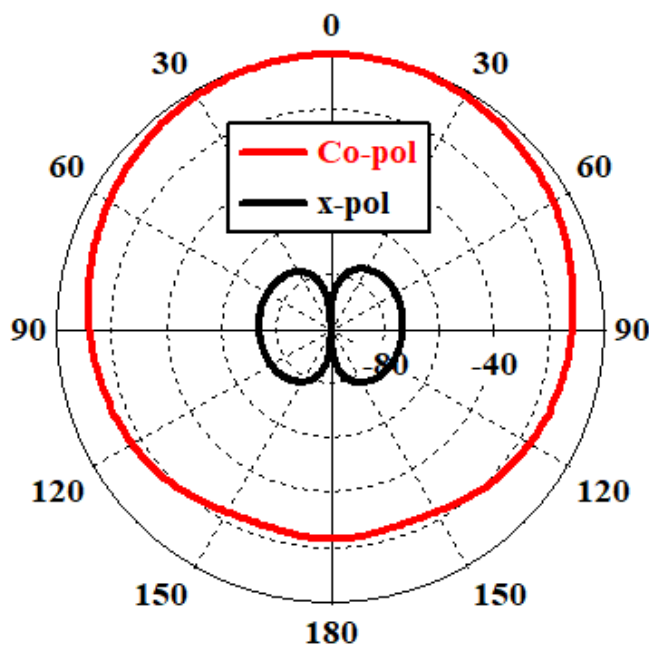

(b)

Fig. 6. Far-field radiation patterns at the resonant frequency for differential port 1 excitation of the proposed antenna. (a) xz-plane. (b) yz-plane.

\section{Conclusions}

In this manuscript, a new differential-fed dual-polarized filtering patch antenna with high gain and high common-mode rejection is presented. Filtering performance is achieved by etching a symmetrical open-loop ring resonator filter to the top layer of the radiating patch. Good 
performance is achieved at the resonant frequency of $3.54 \mathrm{GHz}$ with a realized gain of more than $7.5 \mathrm{dBi}$ around the passband. Furthermore, the performance has exhibited a few attractive features of our presented filtering antenna, that is, high gain, high efficiency, as well as much lower crosspolarization level due to the differentially-driven ports, and complete symmetry of the configuration. The antenna is dual polarized with a height of $0.035 \lambda_{\mathrm{g}}$ and operating at the sub- 6 GHz $5 \mathrm{G}$ spectrum. The designed antenna is simulated and optimized using the CST.

Acknowledgments. This project has received funding from the European Union's Horizon 2020 research and innovation programme under grant agreement H2020-MSCA-ITN-2016 SECRET-722424.

\section{References}

[1] A. Hussaini, "Green Flexible RF for 5G," in Fundamentals of 5G Mobile Networks, J. Rodriguez, Ed.: John Wiley and Sons, 2015, pp. 241-272.

[2] Yasir I.A. Al-Yasir, Hasanain A.H. Al-Behadili, Baha A. Sawadi, Naser Ojaroudi Parchin, Ahmed M. Abdulkhaleq, Abdulkareem S. Abdullah and Raed A. Abd-Alhameed (September 26th 2019). New Radiation Pattern-Reconfigurable 60-GHz Antenna for 5G Communications, IntechOpen, Available from: https://www.intechopen.com/online-first/new-radiation-pattern-reconfigurable-60ghz-antenna-for-5g-communications.

[3] Y. Al-Yasir et al., "Compact tunable microstrip filter with wide-stopband restriction and wide tuning range for 4G and 5G applications," The IET's Antennas and Propagation Conference, 2019, pp. 1-6.

[4] Y. I. Abdulraheem, A. S. Abdullah, H. J. Mohammed, B. A. Mohammed, and R. A. Abd-Alhameed, " Design of radiation pattern-reconfigurable $60-\mathrm{GHz}$ antenna for $5 \mathrm{G}$ applications," Journal of Telecommunications, vol. 52, no. 4, pp. 1-5, 2014.

[5] Y. I. Abdulraheem et al., "Design of frequency reconfigurable multiband compact antenna using two PIN diodes for WLAN/WiMAX applications," in IET Microwaves, Antennas \& Propagation, vol. 11, no. 8, pp. 1098-1105, 2262017.

[6] Y. Liu, S. Wang, N. Li, J. Wang and J. Zhao, "A compact dual-band dual-polarized antenna with filtering structures for sub-6 GHz base station applications," IEEE Antennas and Wireless Propagation Letters, vol. 17, no. 10, pp. 1764-1768, Oct. 2018.

[7] H. J. Mohammed et al., "Evaluation of genetic algorithms, particle swarm optimisation, and firefly algorithms in antenna design," 2016 13th International Conference on Synthesis, Modeling, Analysis and Simulation Methods and Applications to Circuit Design (SMACD), Lisbon, 2016, pp. 1-4.

[8] Y. I. A. Al-Yasir and R. Abd-Alhameed, " New multi-standard dual-wideband and quad-wideband asymmetric step impedance resonator filters with wide stop band restriction," International Journal of RF and Microwave Computer-Aided Engineering, vol. 29, no. 8, p. 1-17, 2019.

[9] Y. Al-Yasir, Y. Tu, N. Ojaroudi Parchin, I. Elfergani, R. Abd Alhameed, J. Rodriguez, J. Noras, "Mixed-coupling multi-function quint-wideband asymmetric stepped impedance resonator filter" Microw. And Opt. Tech. Lett. Vol. 61, no. 5, pp. 1181-1184, Jan. 2019.

[10]X. Gu, S. Nikhil N, L. Guo, S. Hemour and K. Wu, "Diplexer-based fully passive harmonic transponder for sub-6-GHZ 5G-compatible iot applications," IEEE Transactions on Microwave Theory and Techniques, vol. 67, no. 5, pp. 1675-1687, May 2019.

[11] Y. I. A. AI-Yasir, N. Ojaroudi Parchin, A. Alabdullah, W. Mshwat, A. Ullah and R. Abd-Alhameed, "New Pattern Reconfigurable Circular Disk Antenna Using Two PIN Diodes for WiMax/WiFi (IEEE 802.11a) Applications," 2019 16th International Conference on Synthesis, Modeling, Analysis and Simulation Methods and Applications to Circuit Design (SMACD), Lausanne, Switzerland, 2019, pp. 53-56. 
[12] Y. I. A. Al-Yasir, N. O. Parchin, A. Alabdallah, A. M. Abdulkhaleq, R. A. Abd-Alhameed and J. M. Noras, "Design of Bandpass Tunable Filter for Green Flexible RF for 5G," 2019 IEEE 2nd 5G World Forum (5GWF), Dresden, Germany, 2019, pp. 194-198.

[13] Y. I. A. Al-Yasir et al., "Design, Simulation and Implementation of Very Compact Open-loop Trisection BPF for 5G Communications," 2019 IEEE 2nd 5G World Forum (5GWF), Dresden, Germany, 2019, pp. 189-193.

[14] Y. Al-Yasir, N. Ojaroudi Parchin, R. Abd-Alhameed, A. Abdulkhaleq and J. Noras, "Recent Progress in the Design of 4G/5G Reconfigurable Filters" Electronics, vol. 8, no. 1, Jan. 2019.

[15] Y. Al-Yasir, A. S. Abdullah, N. Ojaroudi Parchin, R. A. Abd-Alhameed, and J. M. Noras, "A New Polarization-Reconfigurable Antenna for 5G Applications," Electronics, vol. 7, no. 11, p. 293, 2018.

[16] L. Wen et al., "A Wideband Series-Fed Circularly Polarized Differential Antenna by Using Crossed Open Slot-Pairs," in IEEE Transactions on Antennas and Propagation, vol. 68, no. 4, pp. 2565-2574, April 2020.

[17]Q. Liu, J. Shen, H. Liu and Y. Liu, "Dual-band circularly-polarized unidirectional patch antenna for RFID reader applications", IEEE Trans. Antennas Propag., vol. 62, no. 12, pp. 6428-6434, Dec. 2014.

[18] Al-Yasir Y.I.A. et al. (2019) A New Polarization-Reconfigurable Antenna for 5G Wireless Communications. In: Sucasas V., Mantas G., Althunibat S. (eds) Broadband Communications, Networks, and Systems. BROADNETS 2018. Lecture Notes of the Institute for Computer Sciences, Social Informatics and Telecommunications Engineering, vol 263. Springer, Cham.

[19] Y. I. A. Al-Yasir et al., " A Differential-Fed Dual-Polarized High-Gain Filtering Antenna Based on SIW Technology for 5G Applications," 2020 14th European Conference on Antennas and Propagation (EuCAP), Copenhagen, Denmark, 2020, pp. 1-5.

[20] L. Bian, Y.-X. Guo, L. C. Ong and X.-Q. Shi, "Wideband circularly-polarized patch antenna", IEEE Trans. Antennas Propag., vol. 54, no. 9, pp. 2682-2686, Sep. 2006.

[21] Q.-S. Wu, X. Zhang and L. Zhu, "A wideband circularly polarized patch antenna with enhanced axial ratio bandwidth via co-design of feeding network", IEEE Trans. Antennas Propag., vol. 66, no. 10, pp. 4996-5003, Oct. 2018.

[22] Y. I. A. Al-Yasir et al., "New High-Gain Differential-Fed Dual-Polarized Filtering Microstrip Antenna for 5G Applications," 2020 14th European Conference on Antennas and Propagation (EuCAP), Copenhagen, Denmark, 2020, pp. 1-5.

[23] Al-Yasir, Y.I.A.; Alkhafaji, M.K.; A. Alhamadani, H.; Ojaroudi Parchin, N.; Elfergani, I.; Saleh, A.L.; Rodriguez, J.; Abd-Alhameed, R.A. A New and Compact Wide-Band Microstrip Filter-Antenna Design for 2.4 GHz ISM Band and 4G Applications. Electronics 2020, 9, 1084.

[24] Al-Yasir, Y.I.A.; A. Alhamadani, H.; Kadhim, A.S.; Ojaroudi Parchin, N.; Saleh, A.L.; Elfergani, I.T.E.; Rodriguez, J.; Abd-Alhameed, R.A. Design of a Wide-Band Microstrip Filtering Antenna with Modified Shaped Slots and SIR Structure. Inventions 2020, 5, 11.

[25] Al-Yasir, Y.I.A.; Ojaroudi Parchin, N.; Abdulkhaleq, A.M.; Bakr, M.S.; Abd-Alhameed, R.A. A Survey of Differential-Fed Microstrip Bandpass Filters: Recent Techniques and Challenges. Sensors 2020, 20, 2356.

[26] C. Wang, J. Bian, J. Sun, W. Zhang and M. Zhang, "A survey of 5G channel measurements and models," IEEE Communications Surveys \& Tutorials, vol. 20, no. 4, pp. 3142-3168, Fourth quarter 2018.

[27] S. J. Yang, Y. M. Pan, Y. Zhang, Y. Gao and X. Y. Zhang, "Low-profile dual-polarized filtering magneto-electric dipole antenna for 5G applications," IEEE Transactions on Antennas and Propagation, vol. 67, no. 10, pp. 6235-6243, Oct. 2019.

[28] T. Alam, S. R. Thummaluru and R. K. Chaudhary, "Integration of MIMO and cognitive radio for sub$6 \mathrm{GHz} 5 \mathrm{G}$ applications," IEEE Antennas and Wireless Propagation Letters, vol. 18, no. 10, pp. 2021 2025 , Oct. 2019 
[29] M. E. Yassin, H. A. Mohamed, E. A. F. Abdallah and H. S. El-Hennawy, "Single-fed 4G/5G multiband 2.4/5.5/28 GHz antenna," IET Microwaves, Antennas \& Propagation, vol. 13, no. 3, pp. 286-290, 27 Feb. 2019.

[30] Y. I. A. Al-Yasir et al., "Design of multi-standard single/tri/quint-wideband asymmetric steppedimpedance resonator filters with adjustable TZs," IET Microwaves, Antennas \& Propagation, vol. 13, no. 10, pp. 1637-1645, 14 Aug. 2019.

[31] Y. Al-Yasir, R. A. Abd-Alhameed, J. M. Noras, A. M. Abdulkhaleq and N. O. Parchin, "Design of very compact combline band-pass filter for 5G applications," The Loughborough Antennas \& Propagation Conference (LAPC 2018), Loughborough, 2018, pp. 1-4.

[32]Z. Nie, H. Zhai, L. Liu, J. Li, D. Hu and J. Shi, "A dual-polarized frequency-reconfigurable lowprofile antenna with harmonic suppression for 5G application," IEEE Antennas and Wireless Propagation Letters, vol. 18, no. 6, pp. 1228-1232, June 2019.

[33] T. Hong, Z. Zhao, W. Jiang, S. Xia, Y. Liu and S. Gong, "Dual-band SIW cavity-backed slot array using $\mathrm{TM}_{020}$ and $\mathrm{TM}_{120}$ modes for 5G applications," IEEE Transactions on Antennas and Propagation, vol. 67, no. 5, pp. 3490-3495, May 2019.

[34] Y. I. A. Al-Yasir et al, "Design, simulation and implementation of very compact dual-band microstrip bandpass filter for 4G and 5G applications," 2019 16th International Conference on Synthesis, Modeling, Analysis and Simulation Methods and Applications to Circuit Design (SMACD), Lausanne, Switzerland, 2019, pp. 41-44.

[35] H. Jin, K. Chin, W. Che, C. Chang, H. Li and Q. Xue, "Differential-fed patch antenna arrays with low cross-polarization and wide bandwidths," IEEE Antennas and Wireless Propagation Letters, vol. 13, pp. 1069-1072, 2014.

[36] C. K. Chin, Q. Xue and H. Wong, "Broadband patch antenna with a folded plate pair as a differential feeding scheme," IEEE Transactions on Antennas and Propagation, vol. 55, no. 9, pp. 2461-2467, Sept. 2007.

[37]C. h. k. Chin, Q. Xue, H. Wong and X. y. Zhang, "Broadband patch antenna with low crosspolarisation," Electronics Letters, vol. 43, no. 3, pp. 137-138, 1 Feb. 2007.

[38] M. Arrawatia, M. S. Baghini and G. Kumar, "Differential microstrip antenna for rf energy harvesting," IEEE Transactions on Antennas and Propagation, vol. 63, no. 4, pp. 1581-1588, April 2015.

[39] Q. Xue, S. W. Liao and J. H. Xu, "A Differentially-driven dual-polarized magneto-electric dipole antenna," IEEE Transactions on Antennas and Propagation, vol. 61, no. 1, pp. 425-430, Jan. 2013.

[40] Y. Luo and Q.-X. Chu, "Oriental crown-shaped differentially fed dualpolarized multidipole antenna," IEEE Trans. Antennas Propag., vol. 63, no. 11, pp. 4678-4685, Nov. 2015.

[41] C. R. White and G. M. Rebeiz, "A differential dual-polarized cavity backed microstrip patch antenna with independent frequency tuning," IEEE Trans. Antennas Propag., vol. 58, no. 11, pp. 3490-3498, Nov. 2010.

[42] K. L. Wong, Compact and Broadband Microstrip Antennas. New York: Wiley, 2002, p. 10.

[43] C. R. White and G. M. Rebeiz, “A differential dual-polarized cavity-backed microstrip patch antenna with independent frequency tuning," IEEE Trans. Antennas Propag., vol. 58, no. 11, pp. 3490-3498, Nov. 2010.

[44] G. Adamiuk, W. Wiesbeck, and T. Zwick, "Differential feeding as a concept for the realization of broadband dual-polarized antennas with very high polarization purity," in Proc. IEEE Antennas Propag. Soc. Int. Symp., Charleston, SC, Jun. 2009, pp. 1-4.

[45]C. A. Balanis, Antenna Theory, New Jersey, NJ, USA: John Wiley and Sons, 2015. 